\title{
The Distribution of Synapsin I and Synaptophysin in Hippocampal Neurons Developing in Culture
}

\author{
Tara L. Fletcher, ${ }^{1}$ Patricia Cameron, ${ }^{2}$ Pietro De Camilli, ${ }^{2}$ and Gary Banker ${ }^{1}$ \\ 'Department of Anatomy, Cell Biology, and Neurobiology, Albany Medical College, Albany, New York 12208 and \\ ${ }^{2}$ Department of Cell Biology, Yale University School of Medicine, New Haven, Connecticut 06510
}

\begin{abstract}
As a first step toward elucidating mechanisms involved in the sorting of synaptic vesicle proteins in neurons, we have used immunofluorescence microscopy to determine the distribution of two synaptic vesicle proteins, synapsin I and synaptophysin, in hippocampal neurons developing in culture. In mature cultures, synapsin I and synaptophysin immunoreactivity was concentrated in puncta that were restricted to sites where axons contacted neuronal cell bodies or dendrites. Electron-microscopic immunocytochemistry demonstrated that these puncta corresponded to vesiclefilled axonal varicosities that were exclusively presynaptic. At early stages of development, before cell-cell contact, both synapsin I and synaptophysin were preferentially localized in axons, where they were particularly concentrated in the distal axon and growth cone. In axons that did not contact other cells, immunostaining for these two proteins had a granular appearance, which persisted for at least $7 \mathrm{~d}$, but focal accumulations of vesicles comparable to those seen at sites of synaptic contact were not observed. When neurons contacted one another, numerous puncta of synapsin I and synaptophysin formed within the first week in culture. Double-label immunofluorescence demonstrated that the two vesicle antigens were closely codistributed throughout these stages of development.
\end{abstract}

These observations demonstrate that synaptic vesicle proteins assume a polarized distribution within nerve cells beginning early in development, as soon as the axon can be identified. In contrast, differences in microtubule polarity orientation that distinguish mature axons and dendrites, and that have been proposed to account for the selective sorting of some materials in nerve cells, first appear at a subsequent stage of development. The selective distribution of synaptic vesicle proteins to the axon occurs in isolated cells, independent of interactions with other cells. In contrast, the formation of large clusters of vesicles typical of presynaptic specializations requires contact with an appropriate post-

\footnotetext{
Received July 3, 1990; revised Dec. 18, 1990; accepted Jan. 9, 1991

This research was supported by NIH Grants NS17112 to G.B. and MH45191 to P.D., who was also the recipient of an award from the Muscular Dystrophy Association. We wish to thank Dr. Reinhard Jahn for his generous gift of synaptophysin antisera, Dr. Jeffrey Deitch for his substantial contributions to the electron-microscopic immunocytochemistry, and Colleen Fitzgerald and Cindy Trautman for their expert technical assistance. This paper was submitted by T.L.F. in partial fulfillment of the requirements for the degree of Doctor of Philosophy, Albany Medical Center Graduate School of Health Sciences, Albany, NY.

Correspondence should be addressed to Dr. Gary Banker, Department of Neuroscience, University of Virginia School of Medicine, Medical Center Box 230, Charlottesville, VA 22908.

Copyright (C) 1991 Society for Neuroscience $0270-6474 / 91 / 111617-10 \$ 03.00 / 0$
}

synaptic target. Thus, in cultured hippocampal neurons, the localization of synaptic vesicles in presynaptic specializations is the result of sorting mechanisms intrinsic to individual neurons as well as to mechanisms mediated by cell-cell contact.

The mechanisms that lead to the formation and maintenance of synapses are of critical importance to an understanding of the functional development of the nervous system. The availability of antibodies that recognize specific synaptic vesicle proteins has made it possible to begin to examine some of the cellular events associated with the formation of presynaptic specializations. For example, it has been possible to identify synaptic vesicle antigens in axons and growth cones prior to contact with target cells (Mason, 1986; Sarthy and Bacon, 1985; Chun and Shatz, 1988) and, subsequently, to follow the accumulation of these proteins in varicosities at synaptic sites, for example, at sites opposite $\mathrm{ACh}$ receptor clusters when neurites contact myotubes (Bixhy and Reichardt, 1985; Lupa and Hall, 1989).

The experiments described in this report use this approach to examine changes in the distribution of two synaptic vesicle proteins, synapsin I and synaptophysin (or p38), during the development of CNS neurons in culture. Synapsin I is the collective name for two very similar neuron-specific polypeptides with molecular weights of 86,000 (Ia) and 80,000 (Ib) Da (Ueda and Greengard, 1977), which result from the alternative splicing of the transcript of a single gene (Sudhof et al., 1989). It is a peripheral membrane protein that is associated with the cytoplasmic face of virtually all small synaptic vesicles and is therefore widely distributed in presynaptic specializations throughout the CNS and PNS (De Camilli et al., 1979, 1983a,b; Navone et al., 1984). Synapsin I also binds to cytoskeletal proteins, including F-actin. It is thought to act as a linking protein between small synaptic vesicles and the actin-based cytoskeleton of nerve terminals, thereby mediating the clustering of small synaptic vesicles at release sites (Baines and Bennett, 1985, 1986; Goldenring et al., 1986; Bahler and Greengard, 1987; Petrucci and Morrow, 1987). Synapsin I is a prominent substrate for cAMPdependent and calcium/calmodulin-dependent protein kinases, and its state of phosphorylation is thought to regulate neurotransmitter release by controlling availability of synaptic vesicles for exocytosis (Nestler and Greengard, 1982; Huttner et al., 1983; Llinas et al., 1985; Schiebler et al., 1986). Synaptophysin is an integral membrane glycoprotein, with a molecular weight of $38,000 \mathrm{Da}$ and containing four membrane-spanning domains. It is a major component of small synaptic vesicles in neurons and of a population of small vesicles in neuroendocrine cells (Jahn et al., 1985; Wiedenmann and Franke, 1985; Navone et 
al., 1986; Johnston et al., 1989). It is a calcium-binding protein, and for this reason it is thought to be involved in calciumdependent exocytosis (Rehm et al., 1986). Analysis of its quaternary structure and functional properties suggests that synaptophysin may be a voltage-sensitive, hexameric channel protein (Thomas et al., 1988).

In the present study, we have investigated the distribution of synapsin I and synaptophysin during the development of hippocampal neurons in culture. These cultures have proven to be a useful model system for studying several aspects of neuronal development, including the growth of axons and dendrites and the development of the molecular differences that make these two classes of processes functionally distinct (Caceres et al., 1986; Baas et al., 1988; Dotti et al., 1988; Goslin et al., 1988, 1990). In addition, the axons and dendrites that develop in such cultures form synapses with one another and exhibit a normal synaptic polarity: axons are predominantly presynaptic, and dendrites, postsynaptic (Bartlett and Banker, 1984b). Moreover, the neuronal types present in these cultures normally form synapses with one another in situ, and the properties of such synapses have been extensively studied. Pyramidal neurons, the most abundant cells in the hippocampus, make excitatory connections with one another via recurrent collaterals, Schaffer collaterals, and commissural projections (reviewed by Swanson et al., 1987). Interneurons, including GABAergic cells that make inhibitory connections with pyramidal neurons in situ, have also been identified in these cultures (C. Dotti, unpublished observations). The synapses that form between hippocampal neurons in culture are physiologically functional (C. Allen, unpublished observations) and, when examined by electron microscopy, are comparable in structure to synapses in situ (Bartlett and Banker, 1984b). These features suggest that hippocampal cultures may offer a useful model system for investigating the formation of synapses by CNS neurons.

The aims of the experiments described in this report were to determine the distribution of synapsin I and synaptophysin within individual hippocampal neurons from the earliest stages of their development in culture and to assess how this distribution is influenced by contact with appropriate target neurons. Our results suggest that both vesicle proteins become preferentially distributed to the axon soon after axonal outgrowth, but that the formation of puncta of synapsin I and synaptophysin comparable to those seen at presynaptic specializations in mature hippocampal neurons is triggered by contact between the axon and an appropriate target.

\section{Materials and Methods}

Preparation of hippocampal cell cultures. Cell cultures were prepared from the hippocampi of 18-d-old (E18) fetal rats, as previously described (Banker and Cowan, 1977; Bartlett and Banker, 1984a). Briefly, hippocampi were dissociated by treatment with trypsin $(0.25 \%$ for $15 \mathrm{~min}$ at $37^{\circ} \mathrm{C}$ ) followed by trituration with a fire-polished Pasteur pipette. The cells were plated onto poly-L-lysine treated glass coverslips in minimum essential medium (MEM) with $10 \%$ horse serum at densities ranging from 200 to 16,000 cells $/ \mathrm{cm}^{2}$. After allowing $3-4 \mathrm{hr}$ for the cells to adhere to the substrate, coverslips were transferred into dishes containing a monolayer of astroglial cells (Booher and Sensenbrenner, 1972) so that they were suspended over the glia but were not in contact with them. The cells were maintained in MEM with N2 supplements (Bottenstein and Sato, 1979), ovalbumin $(0.1 \%)$, and pyruvate $(0.1 \mathrm{~mm}$; Selak et al., 1985). Cytosine arabinoside $(5 \mu \mathrm{M})$ was added $3 \mathrm{~d}$ after plating to inhibit the proliferation of non-neuronal cells.

Immunoblots. Samples for electrophoresis were solubilized in $3 \%$ SDS, $10 \%$ 2-mercaptoethanol, $65 \mathrm{~mm}$ Tris- $\mathrm{HCl}(\mathrm{pH}, 6.8)$, and $10 \%$ sucrose, boiled for $2 \mathrm{~min}$, and stored at $-20^{\circ} \mathrm{C}$. After thawing, $15 \mu \mathrm{l}$ of

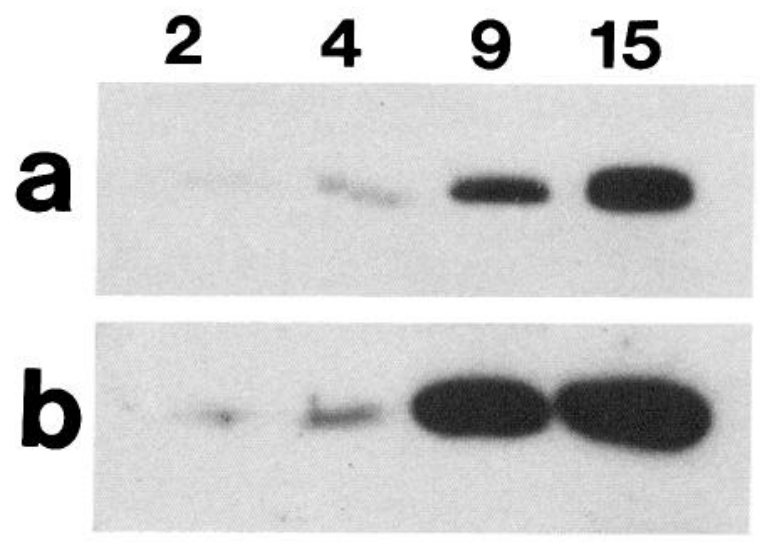

Figure 1. Immunoblots of cultured hippocampal cells stained with antisera directed against synapsin I $(a)$ or synaptophysin $(b)$. Equal volumes of hippocampal cell culture extracts (corresponding to equal numbers of cells) were loaded onto each lane. Numbers at the top of each lane indicate the number of days in vitro. Synapsin I was not resolved as a doublet by the minigel system used.

sample was loaded onto a $7.5 \%$ (synapsin I) or $10 \%$ (synaptophysin) discontinuous polyacrylamide gel and electrophoresed according to the method of Laemmli (1970) using a minigel system (Biorad). The gel was then electroblotted onto nitrocellulose using a semidry transfer apparatus (Biorad) for $35 \mathrm{~min}$ at $1 \mathrm{~A}$ in a buffer containing $25 \mathrm{~mm}$ Tris, $192 \mathrm{~mm}$ glycine, $20 \%$ methanol, and $0.025 \%$ SDS. Blots were processed according to Towbin et al. (1979) using the following buffer for quenching nonspecific protein binding sites, antibody dilutions, and washes: $5 \%$ dry milk, $20 \mathrm{~mm}$ Tris ( $\mathrm{pH}, 7.5$ ), $150 \mathrm{~mm} \mathrm{NaCl}$, and $0.1 \%$ Tween 20 . Immunolabeling was performed with polyclonal rabbit sera directed against synapsin I and against synaptophysin (gift of R. Jahn) followed by incubation with ${ }^{125}$ I protein A (Amersham). These antibodies have been thoroughly characterized previously (De Camilli et al., 1983a; Navone et al., 1986).

Immunofluorescence microscopy. We investigated various protocols for fixation. These included fixation in formaldehyde (4\% depolymerized paraformaldehyde), in a mixture of formaldehyde (4\%) and glutaraldehyde $(0.2 \%)$, and in cold methanol $\left(-20^{\circ} \mathrm{C}\right)$. Following aldehyde fixation, cells were extracted with either ethanol or Triton X-100 $(0.3 \%)$. The distributions of both synapsin I and synaptophysin immunoreactivities were comparable with each of these protocols. The following protocol was used for most experiments because it resulted in the lowest background and best preservation of morphology:

Cultures were fixed for 20 min with warm $4 \%$ formaldehyde in PBS containing $0.12 \mathrm{~m}$ sucrose, permeabilized in $0.3 \%$ Triton X-100 for 5 min at room temperature, and rinsed in PBS. Fixed, permeabilized cultures were sometimes stored for up to $5 \mathrm{~d}$ in PBS containing sodium azide $(0.05 \%)$. Cultures were incubated with $10 \% \mathrm{BSA}$ for $1 \mathrm{hr}$ at $37^{\circ} \mathrm{C}$, then exposed to primary antibody (diluted in 1\% BSA/PBS) overnight at $4^{\circ} \mathrm{C}$. The following primary antibodies were used: affinity-purified rabbit polyclonal anti-synapsin I (1:250); C7.1-C7.4, pooled mouse monoclonal antibodies directed against synaptophysin (1:500; Navone et al., 1986); and AP14, a mouse monoclonal anti-MAP2 (1:400; Binder et al., 1986). After exposure to primary antibodies, the cultures were rinsed in PBS and incubated for $1 \mathrm{hr}$ at $37^{\circ} \mathrm{C}$ with either biotinylated goat anti-mouse IgG or biotinylated goat anti-rabbit IgG (1:800; Vector Laboratories, Burlingame, CA). After rinsing with PBS, cultures were incubated with either rhodamine- or fluorescein-conjugated avidin (1: 1000; Vector Laboratories) for $1 \mathrm{hr}$ at $37^{\circ} \mathrm{C}$. After rinsing with PBS, cultures were mounted in PBS : glycerol (1:1), containing $0.05 \% p$-phenylenediamine (Johnson et al., 1981). For double-label experiments using anti-MAP2, both primary antibodies were incubated together. For the simultaneous localization of synapsin I and synaptophysin, cultures were first exposed to anti-synaptophysin, rinsed, and incubated with $10 \%$ BSA, then exposed to anti-synapsin I. Fluorescein-conjugated goat anti-mouse IgG (1:200; Cappel Laboratories, Cochranville, PA) and biotinylated goat anti-rabbit IgG were then applied together, followed by rhodamine-conjugated avidin. Cultures were photographed using Kodak Tri-X film and developed in Diafine. 

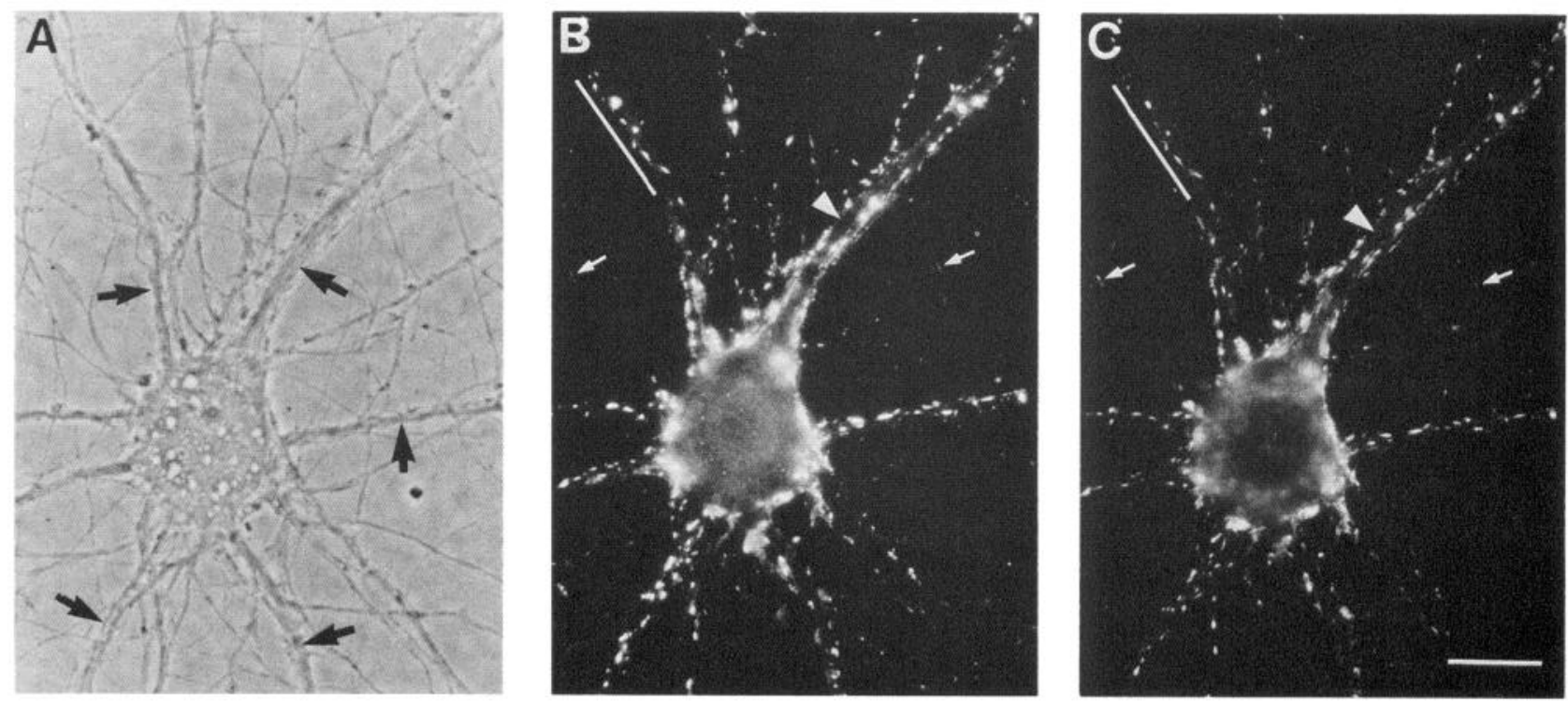

Figure 2. Phase-contrast $(A)$ and fluorescence micrographs illustrating the distribution of synapsin $\mathrm{I}(B)$ and synaptophysin $(C)$ in hippocampal neurons after $23 \mathrm{~d}$ in culture. In such mature cultures, the staining for both synapsin I and synaptophysin was concentrated in brightly fluorescent puncta that surrounded the cell body and outlined the radially oriented, tapering dendritic processes (large arrows). The dendrites themselves appeared devoid of immunoreactivity (arrowheads). In regions where axons did not contact the cell body or dendrites, only a few faintly fluorescent spots of much smaller size could be seen (small arrows). Some of the apparent staining of cell bodies was due to puncta on the upper surface of the cell that were out of the plane of focus. Nearly every spot of synapsin I immunoreactivity was also stained by anti-synaptophysin (solid lines in $B$ and $C$ ). Scale bar, $10 \mu \mathrm{m}$.

Immunoelectron microscopy. Hippocampal cultures, plated and maintained on Aclar coverslips, were fixed in $4 \%$ formaldehyde with $0.2 \%$ glutaraldehyde at $37^{\circ} \mathrm{C}$, then permeabilized with $0.01 \%$ saponin in PBS for $30 \mathrm{~min}$. Coverslips were rinsed in PBS, then reacted with sodium borohydride $(0.5 \mathrm{mg} / \mathrm{ml}$ in PBS). They were blocked with $12 \%$ normal rabbit serum for $1 \mathrm{hr}$ at $37^{\circ} \mathrm{C}$, then exposed to anti-synapsin I antiserum (1:1000 in PBS containing $1 \%$ BSA) overnight at $4{ }^{\circ} \mathrm{C}$. Cultures were then rinsed and incubated with biotinylated goat anti-rabbit IgG $(1: 50)$ for $1 \mathrm{hr}$ at $37^{\circ} \mathrm{C}$ and stained using the Vectastain $\mathrm{ABC}$ procedure (Vector Laboratories). Peroxidase was localized by the formation of reaction product after incubation with diaminobenzidine $(0.05 \%)$ and hydrogen peroxide $(0.001 \%)$ in $50 \mathrm{~mm}$ Tris and $10 \mathrm{~mm}$ imidazole.

Following immunostaining, coverslips were reacted in $1.0 \% \mathrm{OsO}_{4}$ in $0.125 \mathrm{M}$ phosphate buffer for $1 \mathrm{hr}$ at $37^{\circ} \mathrm{C}$ in the dark. They were then rinsed in $3.6 \% \mathrm{NaCl}$ and in $\mathrm{H}_{2} \mathrm{O}$, dehydrated in increasing concentrations of methanol followed by acetone, and embedded in Maraglas (Polysciences, Warrington, PA). After polymerization, the Aclar coverslip was peeled off, and cells were selected and photographed by light microscopy, then punched out of the block and remounted. Thin sections $(80 \mathrm{~nm})$ were counterstained with uranyl acetate and lead citrate and observed on a JEOL 100-CX electron microscope.

\section{Results}

\section{Presence of synapsin I and synaptophysin in cultured} hippocampal neurons

Immunoblot analyses were performed to verify the presence of synapsin I and synaptophysin in hippocampi from E1 8 fetal rats and in cultured hippocampal neurons ranging in age from 2 to $15 \mathrm{~d}$. Synapsin I and synaptophysin were already present in the hippocampus at E18 (not shown), and the expression of both increased throughout the course of development in culture (Fig. 1).

\section{The distribution of synapsin I and synaptophysin in mature hippocampal neurons in culture}

Figure 2 illustrates the distribution of synapsin I and synaptophysin in hippocampal neurons after $23 \mathrm{~d}$ in culture, when both axons and dendrites are well developed. Immunostaining for synapsin I (Fig. $2 B$ ) was concentrated in brightly fluorescent puncta around cell bodies and along tapering, radially oriented processes that have been previously identified as dendrites (Banker and Waxman, 1988). Proximally, where the dendrites were thicker, the puncta appeared to outline their surfaces, while the processes themselves were unstained. Occasional smaller, less intense foci of immunoreactivity could also be detected along axons and axon fascicles. These were barely visible in prints prepared at normal photographic exposures (Fig. $2 B$ ).

The distribution of synaptophysin in the same field is shown in Figure $2 C$. Virtually every spot stained for synapsin I could also be detected following immunostaining for synaptophysin, and vice versa. Occasional small foci of immunostaining could be detected with only one antibody, but in most cases this was attributable to differences in the relative intensity of staining. Low levels of synaptophysin immunoreactivity could also be detected in the perinuclear region of the cell body, where the Golgi complex is located. This was not seen after synapsin I immunostaining, in agreement with previous observations in situ (Navone et al., 1986). The non-neuronal cells present in these cultures contained no detectable immunoreactivity for either synapsin I or synaptophysin (data not shown).

The distribution of synapsin I- and synaptophysin-containing puncta along cell bodies and dendrites is consistent with the distribution of presynaptic boutons in hippocampal cultures, as seen by electron microscopy (Bartlett and Banker, 1984b). To confirm that synapsin I immunoreactivity was primarily associated with presynaptic elements, electron-microscopic immunochemistry was performed (Fig. 3). The foci of immunoreactivity observed by light microscopy corresponded to vesicle-filled axonal profiles that were presynaptic to somata and dendrites. Even in a single section, dozens of synapsin I-positive profiles could be seen contacting the dendrites of an individual 

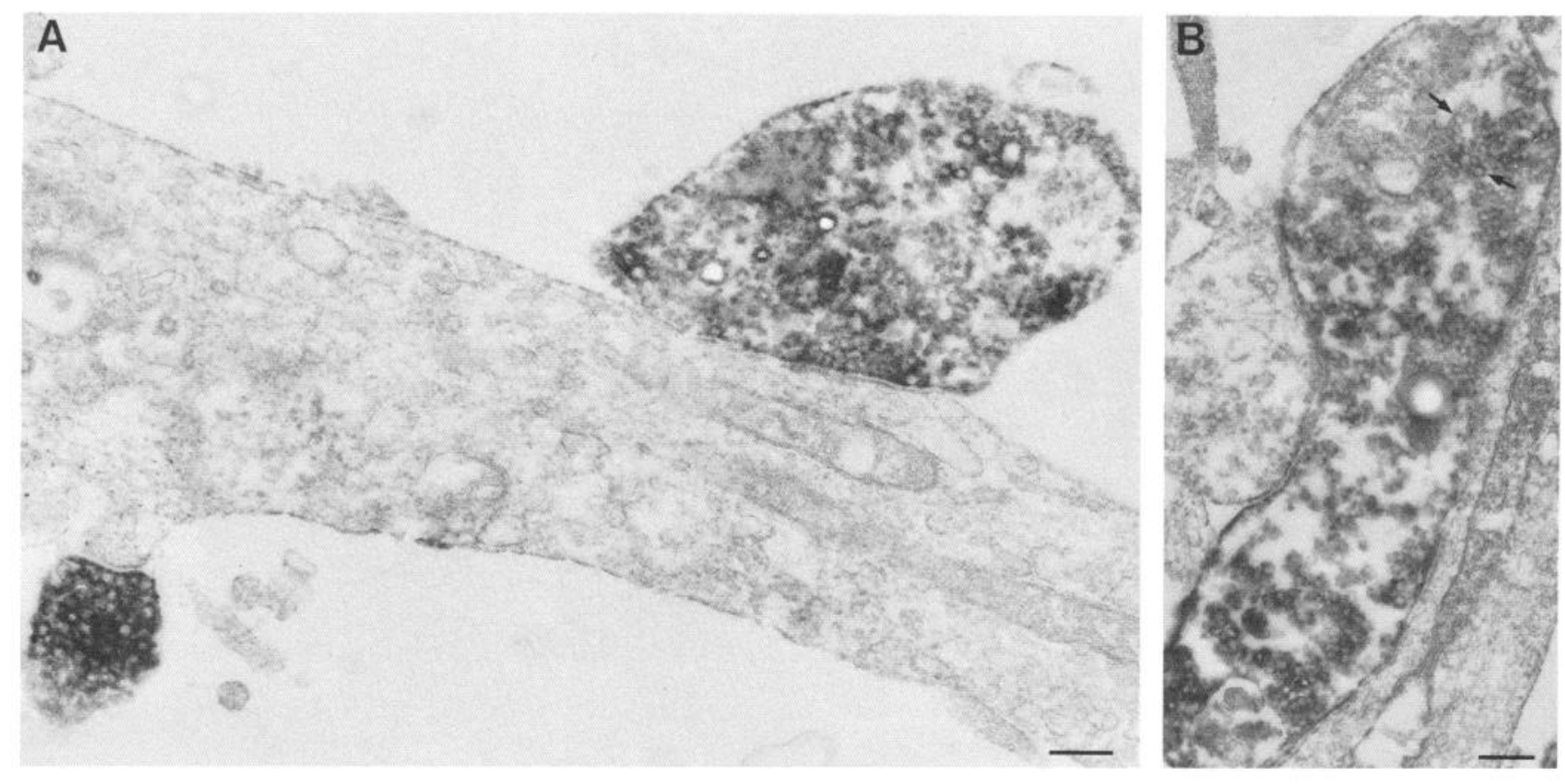

Figure 3. Electron micrographs of 24-d-old cultured hippocampal neurons, illustrating the localization of synapsin I following preembedding immunoperoxidase staining. Vesicle-filled presynaptic profiles, heavily stained with peroxidase reaction product, were apposed to unstained dendrites. Within such boutons, staining appeared to be associated primarily with synaptic vesicles (arrows in $B$ ). Portions of the terminals that lacked vesicles lacked synapsin I immunoreactivity (upper portion of terminal in $B$ ). Scale bars, $0.2 \mu \mathrm{m}$.

cell. The peroxidase reaction product within presynaptic elements appeared to be associated with synaptic vesicles, as described previously (De Camilli et al., 1983b; Huttner et al., 1983). No immunoreactive vesicles were detected within dendrites.

To determine to what extent puncta containing synaptic vesicle antigens were restricted to sites of contact between axons and cell bodies or dendrites, we compared the immunofluorescence distribution of synapsin I with that of MAP2, a specific marker for dendrites (DeCamilli et al., 1984; Caceres et al., 1986). "Synaptic" puncta of synapsin I immunoreactivity surrounded the cell body and were present along the entire dendritic tree. Indeed, the thinnest dendritic branches, which were faintly stained for MAP2, were often better visualized by the synapsin I-stained puncta that surrounded them (arrowheads in Fig. 4B,C). Spots of staining were only rarely seen along presumptive axons (identified by their lack of MAP2 immunostaining), and these spots were typically smaller than "synaptic" puncta. Comparable results were observed when MAP2 and synaptophysin were simultaneously localized (not shown). Taken together, these results suggest that in mature cultures synaptic vesicle antigens are concentrated in presynaptic elements at points of contact between axons and either dendrites or somata.

\section{Changes in the distribution of synapsin I and synaptophysin during neuronal development}

We next examined the localization of vesicle antigens during early stages of neuronal development in culture. Hippocampal neurons initially develop four or five short, "minor processes" that are apparently capable of becoming either axons or dendrites (developmental stage 2 of Dotti et al., 1988). One of these begins to elongate rapidly, becoming the cell's axon (stage 3 ).
The remaining minor processes subsequently become dendrites (stage 4).

The distribution of synapsin I and synaptophysin in individual hippocampal neurons during early stages of development is shown in Figure 5 ( 1 and $2 \mathrm{~d}$ in culture). Both synapsin $\mathrm{I}$ and synaptophysin were expressed by many cells during stage 2 of development, before axonal outgrowth. The staining for both antigens was somewhat granular in appearance and could be detected both in the cell body and in the minor processes (Fig. $5 A-D)$. Although the amount of staining in minor processes varied somewhat from cell to cell, we did not observe instances in which vesicle antigens were selectively concentrated in a single minor process.

The distribution of synapsin I and synaptophysin during stage 3 of development is shown in Figure 5,E-H. At an early stage of axonal outgrowth, synapsin I and synaptophysin were already markedly concentrated in the distal portion of the axon and its growth cone. Only light staining was present in the minor processes of some cells. Later in stage 3, when the axon had extended even farther (Fig. 5I-L), synapsin I and synaptophysin immunoreactivity within the axon increased and occupied a greater length of the distal axon. At this stage, staining for both antigens had a distinctly granular appearance. While these fluorescent spots varied somewhat in size, they were clearly smaller than the "synaptic" puncta of immunoreactivity observed at sites of contact between axons and cell bodies or dendrites in more mature cultures (see Fig. 1). Throughout stage 3, the concentration of synapsin I and synaptophysin in cell bodies remained quite elevated.

The distribution of synapsin I in cells cultured for $5 \mathrm{~d}$, when dendrites were elongating and contacts were being formed between cells (stage 4), is shown in Figure 6. The cells shown were 

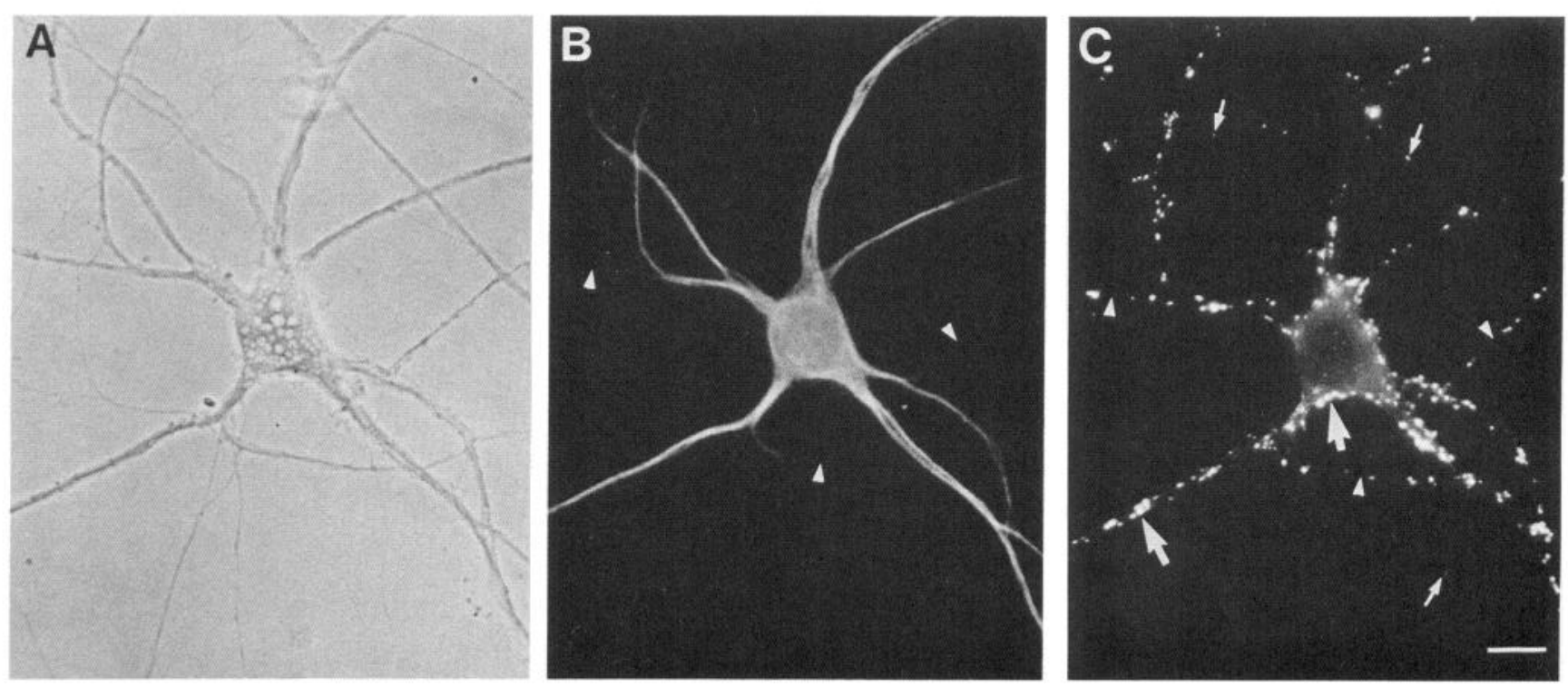

Figure 4. Phase-contrast $(A)$ and fluorescence micrographs comparing the distribution of MAP2 $(B)$ and synapsin I $(C)$ in 19-d-old hippocampal neurons in culture. MAP2 was evident in the cell body and dendrites but was absent from axons. Synapsin I staining was concentrated in discrete puncta (large arrows) along the cell body and dendrites but was rarely found within axons outside their sites of contact with dendrites or somata (small arrows). Some thin dendrites, which were only faintly stained by anti-MAP2, were clearly outlined by rows of anti-synapsin I-stained puncta (arrowheads). Scale bar, $10 \mu \mathrm{m}$.

counterstained with MAP2 antibodies to allow the identification of dendrites. Large puncta of synapsin I immunofluorescence first appeared during this stage, and as in more mature cultures, they were selectively localized to sites of contact between axons and somata or dendrites. These puncta were far fewer in number than those in mature cultures; in fact, many dendrites lacked puncta altogether (arrow in Fig. $6 B, C$ ).

Many of the synaptic puncta appeared to be forming along the length of axons rather than at axonal tips (especially clear in Fig. 6I). This suggests that growth cones do not play an obligatory role in the establishment of definitive presynaptic specializations. The development of "synaptic" puncta appeared to correlate with a decrease in the level of immunoreactivity in axonal segments between puncta. At this stage, only faint synapsin I immunoreactivity was visible in cell bodies, and no significant I immunoreactivity was detectable in dendrites. A similar pattern of localization was observed for synaptophysin (not shown).

\section{The influence of cell-cell contact on the distribution of synaptic vesicle antigens in hippocampal neurons in culture}

To examine the influence of cell contact on the distribution of synapsin I and synaptophysin, hippocampal cultures were prepared at very low plating densities so that some cells developed in the absence of contacts with other cells for several days. A representative example of an isolated cell after $6 \mathrm{~d}$ in culture is shown in Figure 7. Synapsin I staining was primarily restricted to the axon, where it was concentrated in the distal segments and growth cones of nearly every axonal branch (Fig. 7D,E). Although a few, faintly fluorescent, local accumulations of synapsin I could be seen in some preterminal axons (Fig. $7 E$ ), large puncta of synapsin I staining, like those seen at sites of contact between axons and somata or dendrites, were not observed in the axons. Neighboring cells in the same culture that were contacted by axons from other cells exhibited such puncta (com- parable to those illustrated in Fig. 6). The somata and dendrites of isolated neurons, identified by their content of MAP2 (Fig. $7 C$ ), did not contain significant synapsin I staining, and as expected, there were no "synaptic" puncta along their surfaces. The distribution of synaptophysin in isolated hippocampal neurons was comparable to that of synapsin I (not shown).

\section{Discussion}

Before discussing the significance of our observations to the sorting of synaptic vesicles, some consideration of the subcellular localization of the immunostaining is important. In mature cultures, staining of synapsin I and synaptophysin occurred predominantly in large "puncta" that corresponded to presynaptic specializations containing dense accumulations of vesicles. At earlier stages, staining appeared to be associated with fine, particulate elements within the axonal cytoplasm; electron microscopy at these stages reveals clusters of 3-6 small, clear vesicles in axons and axonal growth cones (J. Deitch and G. Banker, unpublished observations). The close correspondence between synapsin I and synaptophysin immunostaining suggests that much of the synapsin I immunoreactivity is associated with synaptophysin-containing membranous elements, even early in development, though it remains possible that a nonmembranous pool of synapsin I went undetected by immunofluorescence, a technique that reveals most effectively sites of high antigen concentration. In cell bodies, elements of the Golgi complex exhibited staining for synaptophysin but not for synapsin I, suggesting that synapsin I associates with vesicles distal to the Golgi complex (see Navone et al., 1986).

\section{Synapsin I and synaptophysin are selectively distributed to the axon prior to synaptogenesis}

Our observations of individual hippocampal neurons demonstrate directly that synaptic vesicles antigens are selectively concentrated within the axon in isolated cells, independent of con- 

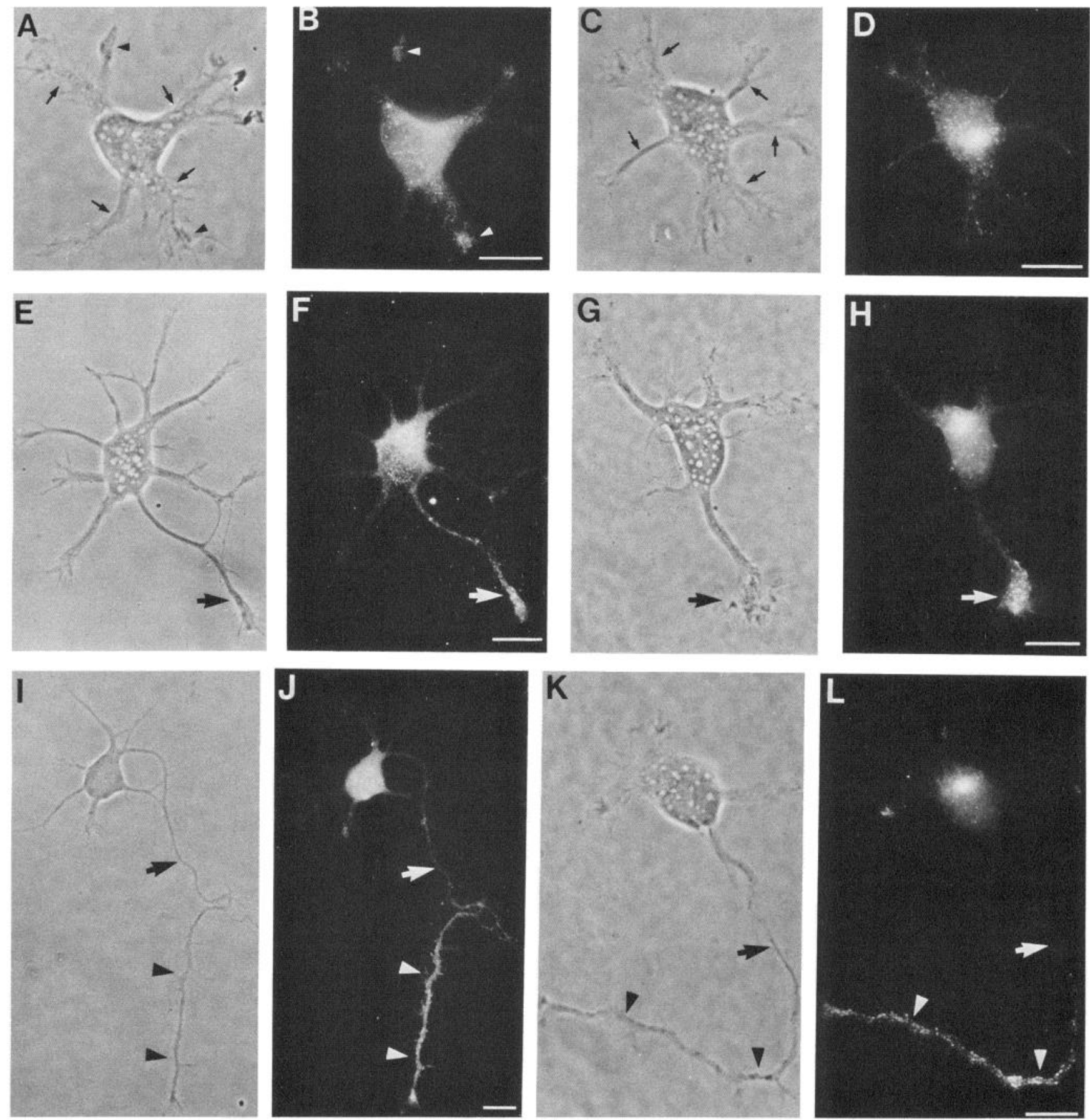

Figure 5. Distribution of synapsin $\mathrm{I}(B, F, J)$ and synaptophysin $(D, H, L)$ at early stages in the development of hippocampal neurons in culture. Cells at Stage 2 of development $(A-D)$ have formed several minor processes (arrows) of approximately equal length, but lack an axon. When present in detectable amounts, synapsin I and synaptophysin were primarily concentrated in the cell body but were also present within the processes $(B$, $D$ ), sometimes at the distal tips (arrowheads in $A, B)$. Early in stage $3(E-H)$, when the outgrowth of the axon (arrow) can first be detected, synapsin I and synaptophysin were concentrated in the distal axon and its growth cone $(F, H)$. Later in stage $3(I-L)$, when the axon $($ arrow) had elongated further, the two proteins were present throughout a longer portion of the distal axon (arrowheads in $J, L$ ). Staining within the axon had a finely punctate appearance. The amount of staining detected in the minor processes at this stage was variable, but in general very low. Scale bars, $10 \mu \mathrm{m}$.

tact with their neuronal targets. Previous studies have demonstrated that synaptic vesicles are present in axons and growth cones (Bixby and Reichardt, 1985; Loffler et al., 1986; Chun and Shatz, 1988; see also Hume et al., 1983; Sun and Poo, 1987), but they have not allowed an assessment of the overall distribution of synaptic vesicles within the nerve cell. Although several other proteins are known to be preferentially localized in axons from the beginning of axonal differentiation, synaptophysin is the first endogenous integral membrane protein found to have such a distribution. In contrast to axonal proteins like GAP-43 and synapsin I that exist in soluble as well as insoluble forms, and whose sorting could occur by any of several mechanisms, the selective distribution of synaptophysin must reflect the intracellular routing of membrane vesicles. Either vesicles 

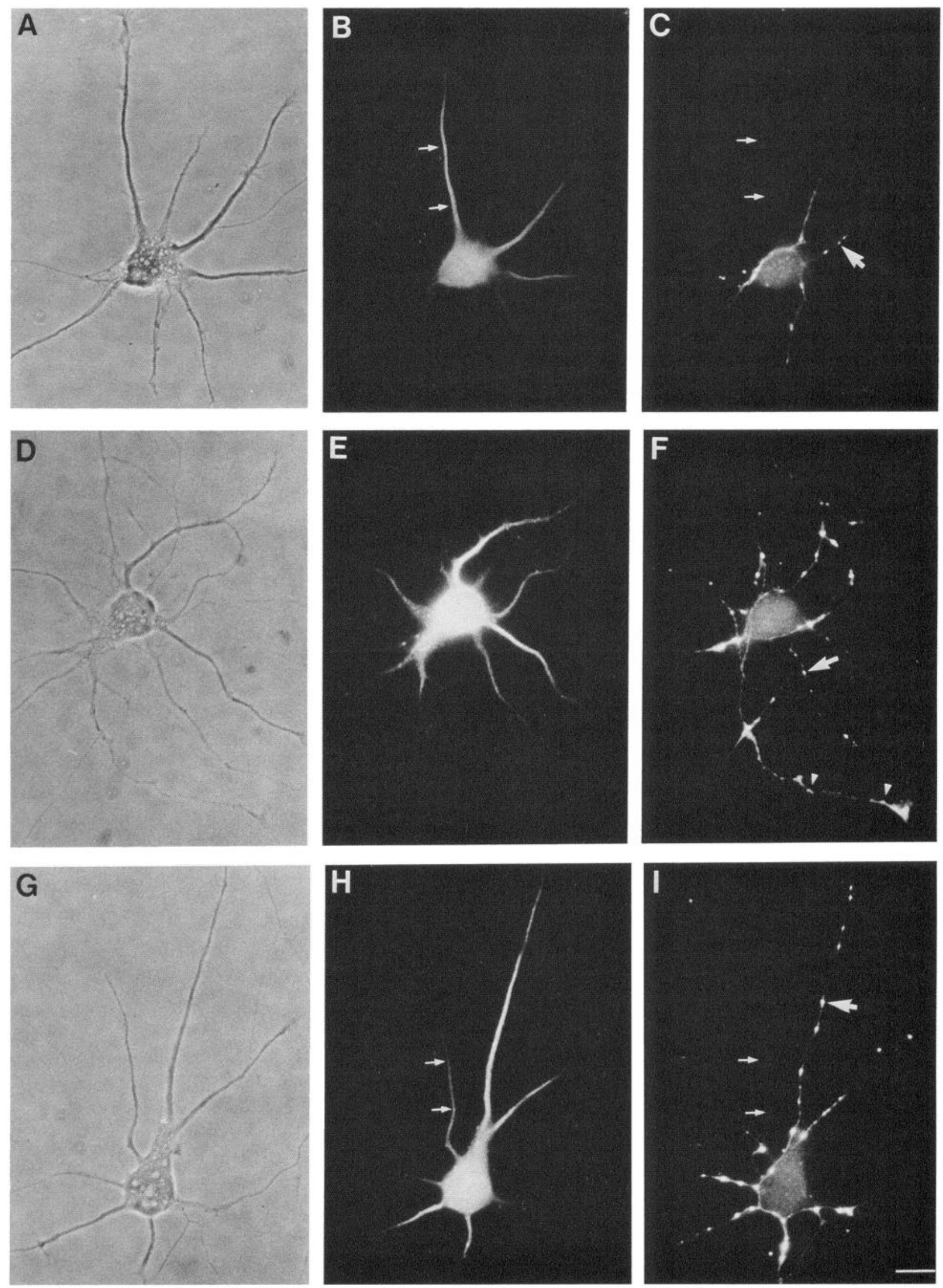

Figure 6. Phase-contrast $(A, D, G)$ and fluorescence micrographs showing the distribution of MAP2 $(B, E, H)$ and synapsin I $(C, F, I)$ in 5 -d-old hippocampal neurons. Synapsin I immunostaining was concentrated in foci within axons at sites where they were in contact with cell bodies or dendrites (large arrows in $C, D, F$ ). Some immunoreactivity within the axonal segments between such foci was also visible. As at earlier stages, the distal portions of axons and axonal growth cones were also stained (arrowheads in F). Only faint staining was apparent in the cell bodies, and dendrites were unstained (small arrows in $B, C, H, I$ ). Scale bar, $10 \mu \mathrm{m}$. 

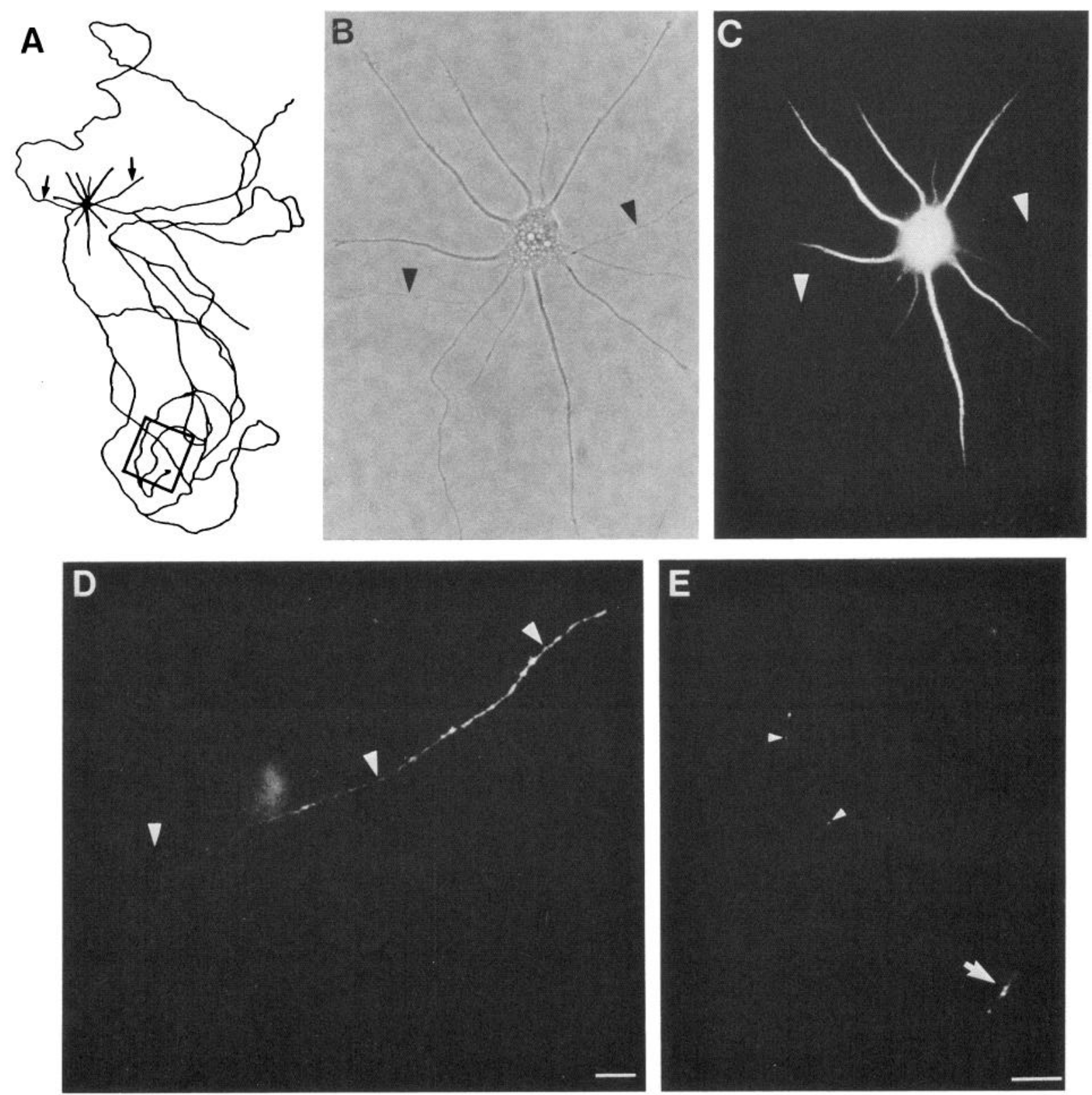

Figure 7. The distribution of synapsin I in an isolated hippocampal neuron after $6 \mathrm{~d}$ in culture. A drawing of the entire cell is shown in $A$. A branch of the axon crossed the cell body (small arrows in $A$ ). The cell body and dendrites are shown by phase-contrast microscopy $(B)$, and after MAP2 and synapsin I immunostaining ( $C$ and $D$, respectively). The dendrites visible by MAP2 immunostaining $(C)$, did not contain detectable synapsin I immunoreactivity, and no large foci of synapsin I immunoreactivity were visible on their surfaces $(D)$. The distal portion of the axonal branch that crossed the cell body and intersected the proximal portions of several dendrites (arrows in $A$, arrowheads in $B-D$ ), was highly immunoreactive for synapsin I. The tips of other axonal branches, for example, the one enclosed by the box in $A$, were similarly synapsin I-positive (arrow in $E$, which shows the field enclosed by the box in $A$ ). A few focal accumulations of synapsin I were visible along preterminal axons (arrowheads in E). Scale bars, $10 \mu \mathrm{m}$.

containing synaptophysin are selectively exported to the axon, or they are transported into all processes but selectively retained within the axon. These results complement the recent observations of Dotti and Simons (1990), who examined the distribution of proteins synthesized by nerve cells following viral infection. They found that viral membrane proteins were sorted selectively into the axonal or somatodendritic domain in a manner that parallels the sorting of viral proteins in polarized epithelial cells.

When the selective accumulation of synaptic vesicles arises is equally important. One attractive mechanism that has been proposed to account for the differential distribution of organelles in neurons is based on the observation that mature axons and dendrites differ in the polarity orientation of their microtubules (Baas et al., 1988; Black and Baas, 1989; De Camilli and Jahn, 1990). Because of this difference, organelles that are primarily transported toward the plus ends of microtubules might be expected to accumulate in the axon, while those that tend to be transported toward the minus ends would accumulate in the cell body and dendrites. However, these differences in microtubule polarity orientation arise during stage 4 of development (Baas et al., 1989), whereas we have shown here that synapto- 
physin is already preferentially segregated to the axonal domain at stage 3 of development. Thus, other mechanisms must account for the differential distribution of membranous elements that arises early in neuronal development.

We have argued previously that the emergence of mechanisms for the selective routing of proteins within nerve cells is closely related to the development of neuronal polarity (Goslin and Banker, 1989, 1990). The present results are consistent with this possibility. Synaptic vesicle antigens were not selectively concentrated in a single process during stage 2 of development, when processes are capable of becoming either axons or dendrites, but became preferentially distributed to the axon during stage 3 , the earliest stage at which the axon can be distinguished morphologically.

\section{Synaptic vesicles cluster in presynaptic specializations following contact with appropriate targets}

As cultures matured and cells became interconnected, large puncta containing both synapsin I and synaptophysin developed at sites of contact between axons and somata or dendrites. These were similar in appearance to synaptic boutons in situ, as revealed by immunostaining of tissue sections with antibodies directed against these proteins (De Camilli et al., 1979, 1983a,b; Navone et al., 1984; Jahn et al., 1985; Wiedenmann and Franke, 1985). Such puncta were rarely observed at sites where axons contacted other axons or glial cells, suggesting that the mechanisms that normally initiate the clustering of synaptic vesicles in cultured hippocampal neurons involve an element of specific cell recognition. Some smaller spots of synapsin I and synaptophysin staining were detected in mature cultures away from sites where axons contacted the somata or dendrites of other cells. Some of these may represent small clusters of synaptic vesicles undergoing transport within the axon (Booj et al., 1986; Baitinger and Willard, 1987), and some may correspond to axoaxonal synapses (though such synapses are rare in hippocampal cultures; Bartlett and Banker, 1984b). In any event, such accumulations represent a relatively small proportion of the total synapsin I and synaptophysin immunoreactivity in mature hippocampal cultures.

Clearly it will be important to elucidate the nature of the interaction with the postsynaptic target that triggers vesicle clustering at presynaptic sites and the resultant changes within the presynaptic element that cause vesicles to cluster. One might imagine that interactions between transmembrane proteins in the axonal plasmalemma and surface components of the postsynaptic cell could trigger changes in the cortical cytoskeleton of the axon, which might in turn change the association between synapsin I and elements of the cortical cytoskeleton (Baines and Bennett, 1985, 1986; Bahler and Greengard, 1987; Petrucci and Morrow, 1987), leading to vesicle aggregation. Immunofluorescence localization of synaptic vesicle proteins in cell culture may offer a useful assay for analyzing the mechanisms underlying the formation of presynaptic specializations.

Contact with appropriate target cells may not be necessary to induce the formation of large vesicle clusters in other types of neurons or in other circumstances. In cultures from the striatum (Weiss et al., 1986) or cerebellum (T. Fletcher, unpublished observations), numerous large immunoreactive puncta are present along neurites at sites that appear to be far from any cell bodies or dendrites, and comparable puncta have been observed in cultures of dorsal root ganglion cells, which do not form synapses with one another (Lah and Burry, 1988). Large synaptic vesicle clusters also occur in situ in neurons that do not form "classical" synapses, such as in aminergic neurons and the nerve terminals of the neurohypophysis (Navone et al., 1989). Even contact with polylysine-coated beads can induce the formation of presynaptic specializations (Burry et al., 1986). Thus, in some circumstances, a wide range of extracellular signals may substitute for interaction with a postsynaptic cell.

\section{Concluding remarks}

The present study suggests the following sequence of events in the development of presynaptic specializations by cultured hippocampal neurons. Major synaptic vesicle proteins, such as synapsin I and synaptophysin, are expressed even before neurons establish a differentiated axon. As soon as the axon develops, these proteins accumulate preferentially in the axon, becoming particularly concentrated in the distal axon and growth cone. When the axon contacts an appropriate target, synaptic vesicle proteins rapidly redistribute to form large puncta of immunoreactivity that correspond to the dense accumulation of vesicles within presynaptic specializations. Concomitantly, the concentration of these proteins in segments between puncta decreases. Thus, the localization of vesicles in presynaptic specializations is the result of sorting mechanisms intrinsic to individual neurons as well as to mechanisms that depend on cell-cell contact.

\section{References}

Baas PW, Deitch JS, Black MM, Banker GA (1988) Polarity orientation of microtubules in hippocampal neurons: uniformity in the axon and nonuniformity in the dendrite. Proc Natl Acad Sci USA 85:8335-8339.

Baas PW, Black MM, Banker GA (1989) Changes in microtubule polarity orientation during the development of hippocampal neurons in culture. J Cell Biol 109:3085-3094.

Bahler M, Greengard P (1987) Synapsin I bundles F-actin in a phosphorylation-dependent manner. Nature 326:704-707.

Baines AJ, Bennett V (1985) Synapsin I is a spectrin-binding protein immunologically related to erythrocyte protein 4.1 . Nature $315: 410$ 413.

Baines AJ, Bennett V (1986) Synapsin I is a microtubule-bundling protein. Nature 319:145-147.

Baitinger C, Willard M (1987) Axonal transport of synapsin I-like proteins in rabbit retinal ganglion cells. J Neurosci 7:3723-3735.

Banker GA, Cowan WM (1977) Rat hippocampal neurons in dispersed cell culture. Brain Res 126:397-425.

Banker GA, Waxman AB (1988) Hippocampal neurons generate natural shapes in cell culture. In: Intrinsic determinants of neuronal form and function (Lasek RJ, Black MM, eds), pp 61-82. New York: Liss.

Bartlett WP, Banker GA (1984a) An electron microscopic study of the development of axons and dendrites by hippocampal neurons in culture. I. Cells which develop without intercellular contacts. J Neurosci 4:1944-1953.

Bartlett WP, Banker GA (1984b) An electron microscopic study of the development of axons and dendrites by hippocampal neurons in culture. II. Synaptic relationships. J Neurosci 4:1954-1965.

Binder LI, Frankfurter A, Rebhun LI (1986) Differential localization of MAP2 and tau in mammalian neurons in situ. Ann NY Acad Sci 466:145-167

Bixby JL, Reichardt LF (1985) The expression and localization of synaptic vesicle antigens at neuromuscular junctions in vitro. J Neurosci 5:3070-3080.

Black MM, Baas PW (1989) The basis of polarity in neurons. Trends Neurosci 12:211-214.

Booher J, Sensenbrenner M (1972) Growth and cultivation of dissociated neurons and glial cells from embryonic chick, rat, and human brain in flask cultures. Neurobiology 2:97-105.

Booj S, Larsson P-A, Dahllof A-G, Dahlstrom A (1986) Axonal transport of synapsin I- and cholinergic synaptic vesicle-like material: further immunohistochemical evidence for transport of axonal cholinergic transmitter vesicles in motor neurons. Acta Physiol Scand 128:155-165. 
Bottenstein JE, Sato GE (1979) Growth of a rat neuroblastoma cell line in serum-free supplemented medium. Proc Natl Acad Sci USA 76:514-519.

Burry RW, Raymond HH, Matthew WD (1986) Presynaptic elements formed on polylysine-coated beads contain synaptic vesicle antigens. J Neurocytol 15:409-419.

Caceres A, Banker G, Binder L (1986) Immunocytochemical localization of tubulin and microtubule-associated protein 2 during the development of hippocampal neurons in culture. J Neurosci 6:714 722.

Chun JJM, Shatz CJ (1988) Redistribution of synaptic vesicle antigens is correlated with the disappearance of a transient synaptic zone in the developing cerebral cortex. Neuron 1:297-310.

De Camilli P, Jahn R (1990) Pathways to regulated exocytosis in neurons. Annu Rev Physiol 52:625-645.

De Camilli P, Ueda-T, Bloom FE, Battenberg E, Greengard P (1979) Widespread distribution of protein $I$ in the central and peripheral nervous systems. Proc Natl Acad Sci USA 76:5977-5981.

De Camilli P, Cameron R, Greengard P (1983a) Synapsin I (protein I), a nerve terminal-specific phosphoprotein. I. Its general distribution in synapses of the central and peripheral nervous system demonstrated by immunofluorescence in frozen and plastic sections. J Cell Biol 96:1337-1354.

De Camilli P, Harris SM, Huttner WB, Greengard P (1983b) Synapsin 1 (protein I), a nerve terminal-specific phosphoprotein. II. Its specific association with synaptic vesicles demonstrated by immunocytochemistry in agarose-embedded synaptosomés. J Cell Biol 96:13551373.

De Camilli P, Navone F, Miller P, Theurkauf WE, Vallee RB (1984) Distribution of microtubule-associated protein 2 (MAP2) in the nervous system of the rat studied by immunofluorescence. Neuroscience 11:819-846.

Dotti CG, Simons K (1990) Polarized sorting of viral glycoproteins to the axon and dendrites of hippocampal neurons in culture. Cell 62:63-72.

Dotti CG, Sullivan CA, Banker GA (1988) The establishment of potarity by hippocampal neurons in culture. J Neurosci 8:1454-1468.

Goldenring JR, Lasher PS, Vallano ML, Ueda T, Naito S, Sternberger NH, Sternberger LA, DeLorenzo KJ (1986) Association of synapsin I with neuronal cytoskeleton. J Biol Chem 261:8495-8504.

Goslin K, Banker G (1989) Experimental observations on the development of polarity by hippocampal neurons in culture. $\mathrm{J}$ Cell Biol 108:1507-1516.

Goslin K, Banker G (1990) Development of neuronal polarity: changes in the distribution of GAP-43 correlate with changes.

Goslin K, Schreyer DJ, Skene JHP, Banker G (1988) Development of neuronal polarity: GAP-43 distinguishes axonal from dendritic growth cones. Nature 336:672-674.

Goslin K, Schreyer DJ, Skene JHP, Banker G (1990) The distribution of GAP-43 during the development of neuronal polarity. J Neurosci 10:588-602.

Hume RI, Role LW, Fischbach GD (1983) Acetylcholine release from growth cones detected with patches of acetylcholine receptor-rich membranes. Nature 305:632-634.

Huttner WB, Schiebler W, Greengard P, De Camilli P (1983) Synapsin I (protein I), a nerve terminal-specific phosphoprotein. III. Its association with synaptic vesicles studied in a highly purified synaptic vesicle preparation. J Cell Biol 96:1374-1387.

Jahn R, Schiebler W, Ouimet C, Greengard P (1985) A 38,000-dalton membrane protein (p38) present in synaptic vesicles. Proc Natl Acad Sci USA 82:4137-4141.

Johnson G, Gloria M, Noghueira Araujo C (1981) A simple method of reducing the fading of immunofluorescence microscopy. J Immunol Methods 43:349-350.

Johnston P, Jahn R, Sudhof TC (1989) Transmembrane topography and evolutionary conservation of synaptophysin. J Biol Chem 264 1268-1273.

Laemmli UK (1970) Cleavage of structural proteins during the assembly of the head of bacteriophage T4. Nature 227:680-685.

Lah JJ, Burry RW (1988) Expression and distribution of synaptic vesicle protein SVP65 in cultured dorsal root ganglion neurons. Soc Neurosci Ábstr 14:514.
Llinas R, McGuinness TL, Leonard CS, Sugimori M, Greengard P (1985) Intraterminal injection of synapsin I or calcium/calmodulindependent protein kinase II alters neurotransmitter release at the squid giant synapse. Proc Natl Acad Sci USA 82:3035-3039.

Loffler F, Lohmann SM, Walckhoff B, Walter U, Hamprecht B (1986) Immunocytochemical characterization of neuron-rich primary cultures of embryonic rat brain cells by established neuronal and glial markers and by monospccific antiscra against cyclic nuclcotidc-dependent protein kinases and the synaptic vesicle protein synapsin I. Brain Res 363:205-221.

Lupa MT, Hall ZW (1989) Progressive restriction of synaptic vesicle protein to the nerve terminal during development of the neuromuscular junction. J Neurosci 9:3937-3945.

Mason CA (1986) Axon development in mouse cerebellum: embryonic axon forms and expression of synapsin I. Neuroscience 19:13191333.

Navone F, Greengard P, De Camilli P (1984) Synapsin I in nerve terminals: selective association with small synaptic vesicles. Science 226:1209-1211.

Navone F, Jahn R, Di Gioia G, Stukenbrok H, Greengard P, De Camilli $P$ (1986) Protein p38: an integral membrane protein specific for small vesicles of neurons and ncurocndocrinc cells. J Ccll Biol 103: 2511-2527.

Navone F, Di Gioia G, Jahn R, Browning M, Greengard P, De Camilli P (1989) Microvesicles of the neurohypophysis are biochemically related to small synaptic vesicles of presynaptic nerve terminals. J Cell Biol 109:3425-3434.

Nestler EJ, Greengard P (1982) Nerve impulses increase the phosphorylation state of protein I in rabbit superior cervical ganglion. Nature 296:452-454.

Petrucci TC, Morrow JS (1987) Synapsin I: an actin-bundling protein under phosphorylation control. J Cell Biol 105:1355-1363.

Rehm H, Wiedenmann R, Betz H (1986) Molecular characterization of synaptophysin, a major calcium-binding protein of the synaptic vesicle membrane. EMBO J 5:535-541.

Sarthy PV, Bacon W (1985) Developmental expression of a synaptic vesicle-specific protein in the rat retina. Dev Biol 112:284-291.

Schiebler W, Hahn R, Doucet J-P, Rothlein J, Greengard P (1986) Characterization of synapsin I binding to small synaptic vesicles. J Biol Chem 261:8383-8390.

Selak I, Shaper SD, Varon S (1985) Pyruvate participation in the low molecular weight trophic activity for central nervous system neurons in glia-conditioned medium. J Neurosci 5:23-28.

Sudhof TC, Czernik AJ, Kao H-T, Takei K, Johnston PA, Horiuchi A, Kanazir SD, Wagner MA, Perin MS, De Camilli P, Greengard P (1989) Synapsins: mosaics of shared and individual domains in a family of synaptic vesicle phosphoproteins. Science 245:1474-1480.

Sun Y-A, Poo MM (1987) Evoked release of acetylcholine from growing embryonic neurons. Proc Natl Acad Sci USA 84:2540-2544.

Swanson LW, Kohler C, Bjorklund A (1987) The limbic region. I. The septohippocampal system. In: Handbook of chemical neuroanatomy, Vol 5 (Bjorklund A, Hokfelt T, Swanson LW, eds), pp 125-277. New York: Elsevier.

Thomas L, Hartung K, Langosch D, Rehm H, Bamberg E (1988) Identification of synaptophysin as a hexameric channel protein of the synaptic vesicle membrane. Science 242:1050-1053.

Towbin H, Staehelin T, Gordon J (1979) Electrophoretic transfer of proteins from polyacrylamide gels to nitrocellulose sheets: procedures and some applications. Proc Natl Acad Sci USA 76:4350-4354.

Ueda T, Greengard P (1977) Adenosine 3':5'-monophosphate-regulated phosphoprotein system of neuronal membranes. I. Solubilization, purification, and some properties of an endogenous phosphoprotein. J Biol Chem 252:5155-5163.

Weiss S, Pin J-P, Sebben M, Kemp DE, Sladeczek F, Gabrion J, Bodkaert J (1986) Synaptogenesis of cultured striatal neurons in serumfree medium: a morphological and biochemical study. Proc Natl Acad Sci USA 83:2238-2242.

Wiedenmann B, Franke WW (1985) Identification and localization of synaptophysin, an integral membrane glycoprotein of $M_{r} 38,000$ characteristic of presynaptic vesicles. Cell 41:1017-1028. 